\title{
Hermeneutical Engineering of Requirements
}

\author{
Wagner Varalda, Ítalo S. Vega \\ Program of Intelligence Technologies and Digital Design, Pontifical Catholic University of São Paulo, São Paulo, Brazil \\ Email: wagnervaralda@uol.com.br, italo@pucsp.br
}

How to cite this paper: Varalda, W. and Vega, Í.S. (2017) Hermeneutical Engineering of Requirements. Journal of Computer and Communications, 5, 7-16. https://doi.org/10.4236/jcc.2017.52002

Received: December 7, 2016

Accepted: February 4, 2017

Published: February 7, 2017

Copyright $\odot 2017$ by authors and Scientific Research Publishing Inc. This work is licensed under the Creative Commons Attribution International License (CC BY 4.0).

http://creativecommons.org/licenses/by/4.0/

\begin{abstract}
The Software Engineering aims to develop, within the deadlines and costs established, quality software and that meets the needs of its users. To be made the definition of what the software should do (to establish its purpose), it included the execution of activity the Requirements Engineering, where the context of software to be developed is identified, examined and specified. All other activities of software development depend primarily on this activity. However, there is a problem increasingly in evidence: understand the context of software to be developed. This article aims to present a proposal to face this problem through the use of specific hermeneutical methods for the Requirements Engineering, which will help the software development team understand the original needs of the business to be attended. The basic idea is to produce a hermeneutic specification acceptable, which will be used for the extraction and the specification of the software requirements to be developed. In essence, the hermeneutics focuses on the true interpretation and understanding in contextualized of what is intended to know. The Hermeneutical Engineering of Requirements comes to be the result of the adequacy of methods hermeneutical to assist, specifically the activity of Engineering of Requirements.
\end{abstract}

\section{Keywords}

Software Development, Requirements Engineering, Hermeneutics, Hermeneutical Methods

\section{Introduction}

Within deadlines and costs established, develop quality software that meets the needs of its users; this has been (and still is) the great challenge of software engineering, as have shown the several studies of the area. Notable are the results of the report of chaos (The Chaos Report): $94 \%$ of projects that start should be initiated because the applications did not meet the expected characteristics, resulting, on average, increase $128 \%$ of the cost initially estimated for the project 
and $222 \%$ in the period initially estimated for the project [1]. These figures point to a number of difficulties to be overcome in software projects. Most of the time, we see that the disability is the difficulty in extracting and understanding the needs to be met by the software to be developed and to specify the requirements of this software.

At the beginning of software, development lays the Requirements Engineering activity, whose realization should establish what the software should do. This involves defining your desirable and necessary behavior so that they are attended the business need for which will be developed. The Requirements Engineering defines the project vision, where the scope is detailed to know the fundamental requirements to be met, the features to be made available, the existing restrictions, the established interfaces, the information to be processed, the performance desired, the problems to be solved and the required validation criteria for evaluation and approval from software [2]. The software, then, will be designed and built according to what was established by the Requirements Engineering. Therefore, the quality of the software will be, at most, as good as the quality of the vision of the project defined by the Requirements Engineering. The problem of software development, here shown, is the understanding of the concerns and practical needs to be met by the software to be developed.

The Hermeneutical Engineering of Requirements is a proposal to ensure that the exact context of the software to be developed is identified, examined and specified. Thus, the Software Engineering will define the vision of software development project with improved precision.

\section{Elements of Hermeneutics}

It is not the purpose of this article discuss in detail about the appearance and the evolution of hermeneutics. Still, some points are relevant to support the proposal presented in this article. The Hermeneutics is the science that establishes the principles, laws and the methods of the human process of interpretation. Relates to understanding and the interpretation to analyze the meaning in the field of inter-subjectivity, comprising and interpreting the meaning of things, and also identifying and studying the laws governing these things. The Hermeneutics establishes a reflective thinking that leads to true interpretation and contextualized understanding of what is intended to know.

Until the XIX century, hermeneutics developed as an auxiliary discipline to science, to guide, in normative form, in understanding and interpretation of the ancient literary classics [3]. From that century, hermeneutics has acquired a new dimension, releasing this of practices and rules of hermeneutic existing until then, and begins to acquire character scientific, whose maturity is achieved in the XX century [3].

With Friedrich Schleiermacher (1768-1834), through hermeneutics is possible to avoid misunderstanding and misunderstanding. Its fundamental interest is mediate the strange relationship between thinking and speaking. One who interprets, understand speech as well as the author and then even better than him. 
This is possible due to psychological interpretation, which completes the grammatical interpretation and finds the mental intention of the author [3].

With Wilhelm Dilthey (1833-1911), the Sciences of the spirit coalesce with the Hermeneutics. The problems logics and gnosiological concerning the justification of the historical knowledge form the core of a hermeneutics that has as its main task the knowledge and the description of the laws of the spiritual life, which constitute the basis of the different human sciences. Thus, hermeneutics becomes the universal theory of understanding and interpretation the significant objectivations of the life historical and your fundamental core lies in the possibility that has historical awareness to rebuild, from the meanings of life, fixed with long-term effect, the intention and circumstances from the author. (As well as Schleiermacher, rebuild something whose key should be sought in the author's intention) [3].

With Martin Heidegger (1889-1976), the hermeneutics reaches a whole new meaning. Leaves definitely the psychological and epistemological record and passed to the central issue of philosophizing. In his work "Being and Time" by 1927, understanding hermeneutics appears linked to the requirement urgent for the replacement of the question of the meaning of "be", and strengthen the question of historicity as a hermeneutic question, to house the mystery of Temporality. This question is essential for the Constitution of Dasein (this concept is refined in Section 2.1). From this point the hermeneutics acquires ontological roots deep, to dismantle the psychological interpretation and find a great and new horizon [3].

The Hermeneutics as clarification of the ontological phenomenon of understanding, featuring the mode of existence, aligns with the vision of Hans-Georg Gadamer (1900-2002). Essentially, this was the contribution left by Heidegger and used by Gadamer in his work "Truth and Method", 1960. The hermeneutics cannot be thought of as an action of subjectivity, but as a process in the place of tradition itself. All understanding develops in the place of language or the transmission and assumptions that mark the rooting of the subject in a world it has been said or meaning. Therefore, "only the recognition of the character essentially marked by prejudice of all understanding gives to the hermeneutical problem the real sharpness". Understand now is to translate and question the process of spiritual transmission that is the human humanity, according to a dialectical logic called appropriation or application. Interpreting is not rebuild or coincide, get only the cognitive dimension of said, but understand itself in the light of the text. Is to translate to the horizon of the present the sense of the questions to which answers the text and answer them with the concepts of present [3].

With Paul Ricoeur (1913-2005), the hermeneutics becomes more critical and the phenomenon of language receives significant importance through language sciences. Pops up also a concept of explanation closely linked to the scope of the humanities, where the hermeneutics needs to go of the ontological primacy of understanding, and answer the properly semantic moment of this and on this realizes the indication that understanding is really a way of being. So, the idea of 
existence as a being that is given through the interpretation, should be enriched from a semantic elucidation of the signs of exist and how these refer beyond himself [3].

The Hermeneutical Engineering of Requirements is the result of the adequacy of the concepts Dasein and Hermeneutic Circle (detailed respectively in Sections 2.1 and 2.2) proposed by Martin Heidegger, to help specifically the Requirements Engineering activity, from Software Engineering.

\subsection{Triad of Dasein}

In his work "Being and Time", Heidegger ponders about the term "Being". He is not based on the question of "Being" of "Entity" of the things (consisting of simple presence in the world), but on the "Being" of "Entity" of man, the only "Entity" capable of to question about the "Being". The "Being" of man does not consist in a mere presence in the world, but in a "Being-there" (Dasein), which is defined from the following elements: "being-in-the-world", "being-with-other" and "being-for-death" [4]. Figure 1 illustrates the triad of Dasein.

The element "being-in-the-world" establishes a condition of imminence, where the "Being" is revealed internally. The Dasein speaks of himself, sees himself, wonders about his ontological character (refers to the subject in itself, in its unrestricted complexity and essential). Has a world that is going to meet it and put it in context. Your understanding and interpretation is given as discovering and revealing the ways of relation (or life) of "being-with-this-world". Launching to the world, the Dasein surrenders to occupations and then finds his way of "being-in-the-world" [5].

Dasein is present in a world and this presence has an openness to Dasein to give it meaning to this world. The Entity as a subject of Dasein is contextualized through its various possibilities of being, which occur through the occupations of the instruments produced and belonging to this world, where each instrument generally refers to other instruments. The Entity, then, with the use of these

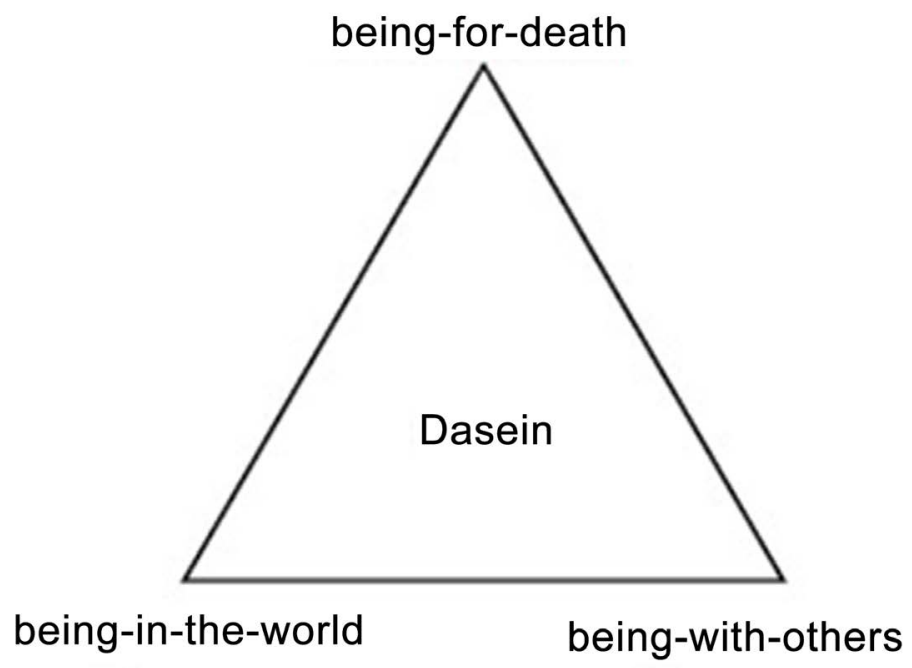

Figure 1. Triad of Dasein. 
instruments, carries out its projects. Figure 2 illustrates the context of "Beingin-the-world".

The element "being-with-others" establishes the transcendence condition. The Dasein sharing with others the space that surrounds you. In his occupation, he find yourself and also find with others. Without the other, there is no use. Be launched in the world enables the Dasein share this world with others. The other is always perceived as "being in the world", produces something-does something to someone. The Dasein lives in this world, but not alone, is constantly connecting "with-others" [6].

The world that opens to Dasein is the surrounding world, which has been contextualized from ancient times to the present; Is the historical world, marked and contextualized by temporality. This is the world shared by Dasein. This surrounding world is manifested in the here and now, in the present, which comes to be the everyday world. From this everyday world, the beings coexist in a circumstantial world, that comes to be the environment shared by the entities for the accomplishments of their projects. Figure 3 illustrates the context of "being-with-others".

The element "being-for-death" sets the condition of being and existence. The Dasein, when released "in the world" and in communion "with-others", gives meaning to its existence. He can choose, for example, his profession and field of study. In the choices he makes, on the numerous possibilities, he is being, i.e., he is existing. Among the variety of possibilities, there is one that cannot choose: choose not die. The authentic life is involved with the possibility of death-only the that cannot choose and not on the mundane possibilities. As a possibility, death is the most proper of Dasein. It has nothing to do with each other, much less with things. Death happens to every man, and thus individually, man experiences it; and one cannot interfere in any way in the death of another. The act of dying puts the Dasein in a radical departure from the other, which is an indicator positively that this time the man is able to understand about yourself authentically, from its own existence. In addition, death, as a possibility, marks the

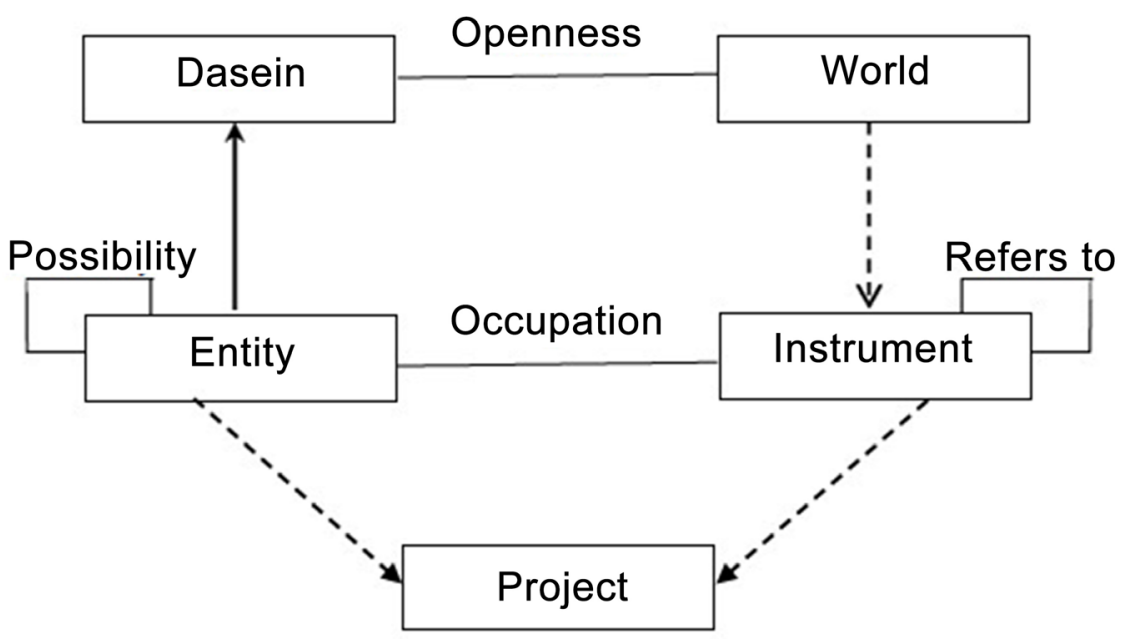

Figure 2. Dasein: element "being-in-the-world". 


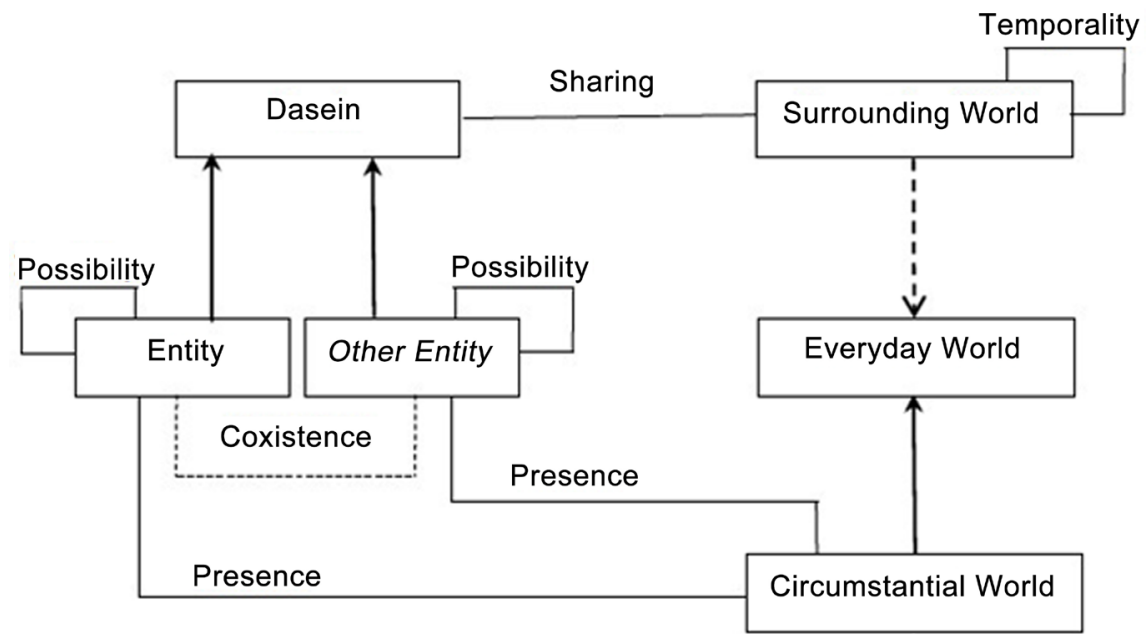

Figure 3. Dasein: element "being-with-others".

absence of other possibilities. In this perspective, death is imminent, is the possibility of the impossibility of "being in the world". The "being-for-death" shows to Dasein that one day, it will not be another "being in the world" and too it will not be another "being-with-others". Is the vision of existential limit, which allows you to witness about the "being" in its entirety [7].

Dasein seeks to give meaning to certain phenomena he perceives, especially to the phenomena of existence, death, birth and communication, each entity being related in a different way to these phenomena. Existence arouses curiosity to the entity, while death generates anxiety and surprise birth. In relation to communication, it occurs through language. Figure 4 illustrates the context of "being-towards-death".

\subsection{Hermeneutic Circle}

The hermeneutic circle has a positive ontologically sense in understanding, because it allows the interpreter to prepare a project on what will interpret; but in the course of interpretation it is possible the development of a new project, followed by another and another more successively. In this sense, the pre-concepts and the pre-understandings, that the interpreter has over text, they have room to be put to the test and thus highlight the possibility for a coherent understanding [8]. Figure 5 illustrates the triad of Hermeneutic Circle.

\section{Hermeneutical Engineering of Requirements}

The Hermeneutical Engineering of Requirements (HER), central purpose of this article, aims to ensure that the exact context of software being developed are identified, examined and specified. Thus, the Software Engineering will define the vision of software development project with improved accuracy. As a general objective, the idea is to adapt and propose the use of hermeneutical methods that will help software development team to understand the unique needs of the business to be met, so that a hermeneutics specification acceptable is produced, Which will be used for the extraction and the specification of the software re- 


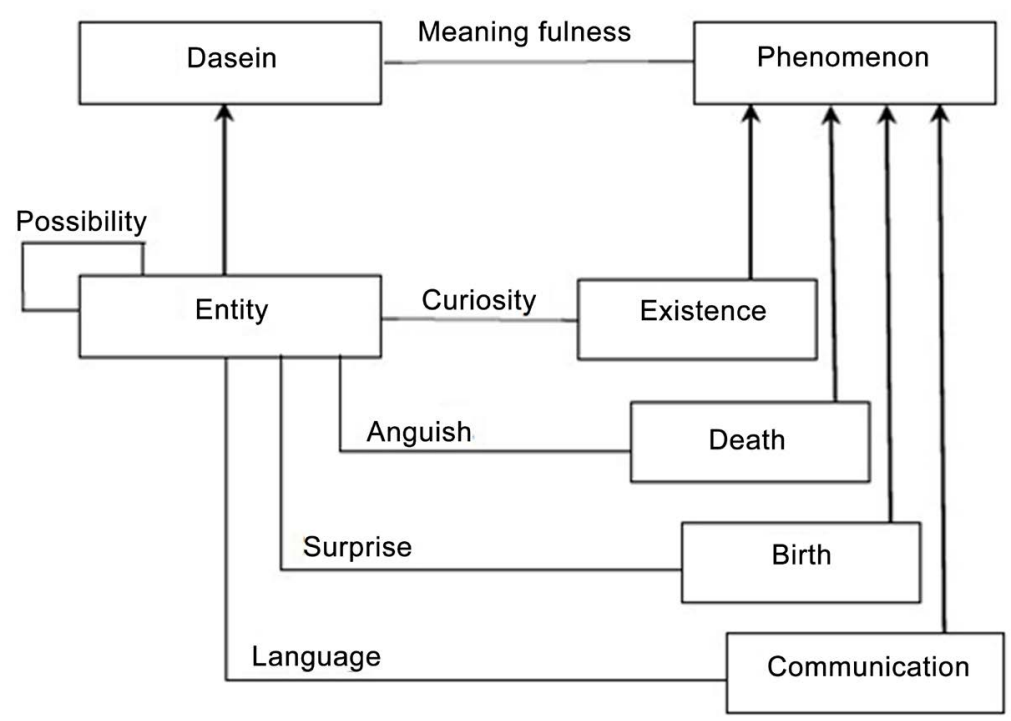

Figure 4. Dasein: element "being-for-death".

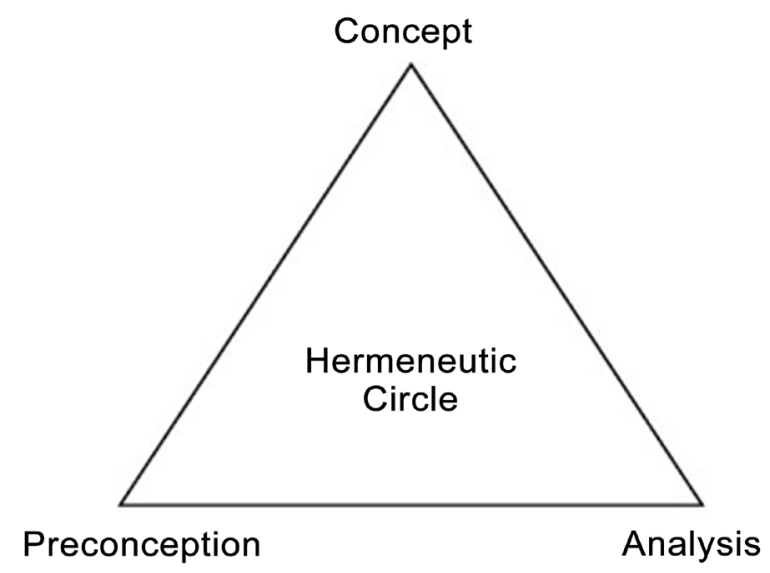

Figure 5. Triad of hermeneutic circle.

quirements to be developed. From a more specific point of view, we propose a set of hermeneutical methods for the interpretation of the original business requirements to be met; we propose the production of acceptable hermeneutics specification, through mechanisms that incorporate the hermeneutical methods of interpretation of the original business requirements to be met; we propose extraction techniques of requirements of software of acceptable hermeneutics specification. Figure 6 illustrates the triad of HER, whose elements will soon be set out below.

\subsection{Identification of Situational Difference}

When the business need is identified, or when discovering a new service or potential market, stakeholders in the business community define a business plan, analyze its feasibility, and make an operational description of the project scope. This information, subject to change, is sufficient to elicit discussions with software engineers [2]. Figure 7 illustrates the context of Situational Difference 


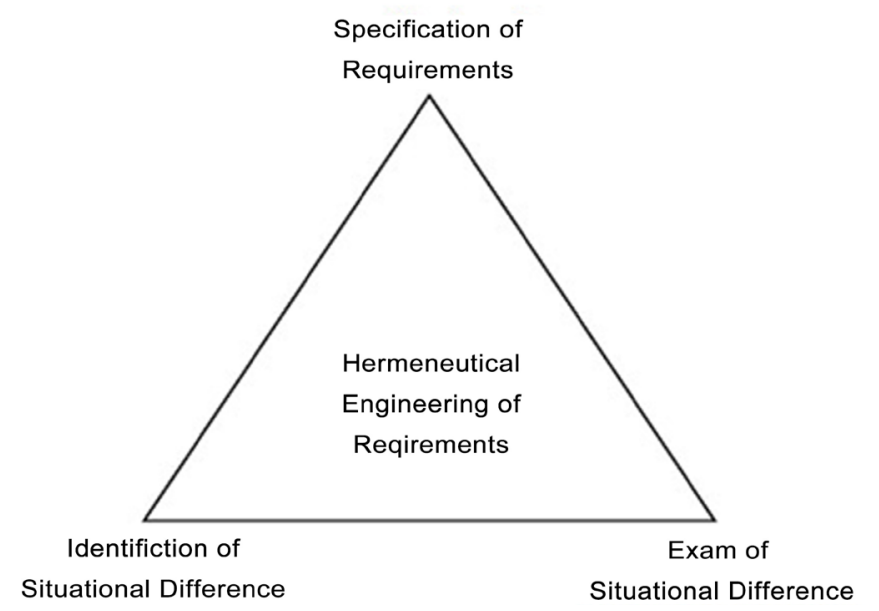

Figure 6. Triad of HER (Hermeneutical Engineering of Requirements).

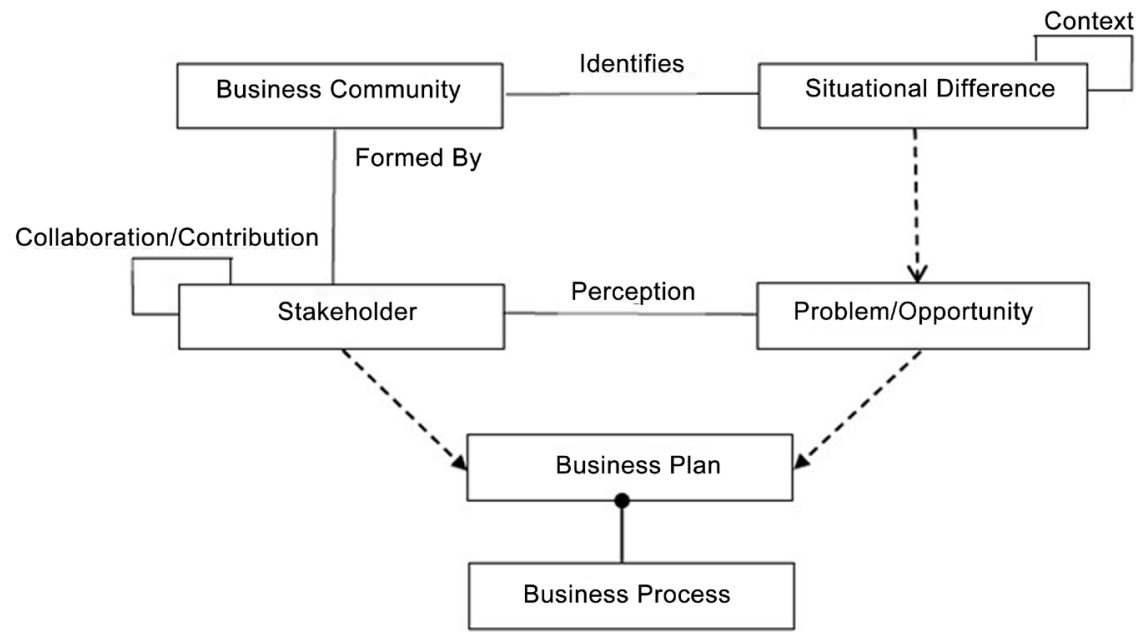

Figure 7. HER: element identification of situational difference.

Identification, which is identified by the business community and perceived as a problem and/or opportunity by one of its members (interested in the situational difference). As a result, it produces a business plan to deal with the problem and/ or opportunity. The production of that plan results in a business process, eventually the target of a technological support.

\subsection{Exam of Situational Difference}

Once situational differences are identified, through their business problems and/ or opportunities, they should be examined to discover the circumstances that lead to or lead to such problems and/or opportunities, so that a range of possibilities and benefits for the business community can be extracted and converted into software requirements. Figure 8 illustrates the context of the Situational Difference Examination.

For each Problem/Opportunity, one must identify the suggestions and guidelines for its solution/implementation (this must be done with the interested parties that perceive it). Each Problem/Opportunity depends on a set of circums- 
tances to contextualize. From this context, we extract the set of possibilities (with their respective benefits) of transforming them into software requirements.

\subsection{Specification of Requirements}

As situational differences are examined, they can already be declared as Original Needs, where the expectations of the stakeholders of the business community will be made explicit. Next, the acceptable software specification will be produced, and from there the software requirements will be specified. Throughout this process, the stakeholders of the business community should approve the artifacts produced by the Requirements Engineer and the communication between the Stakeholders and the Requirements Engineer will be given through the hermeneutic methods proposed by the Hermeneutical Engineering of Requirements. Figure 9 illustrates the context of the Requirements Specification.

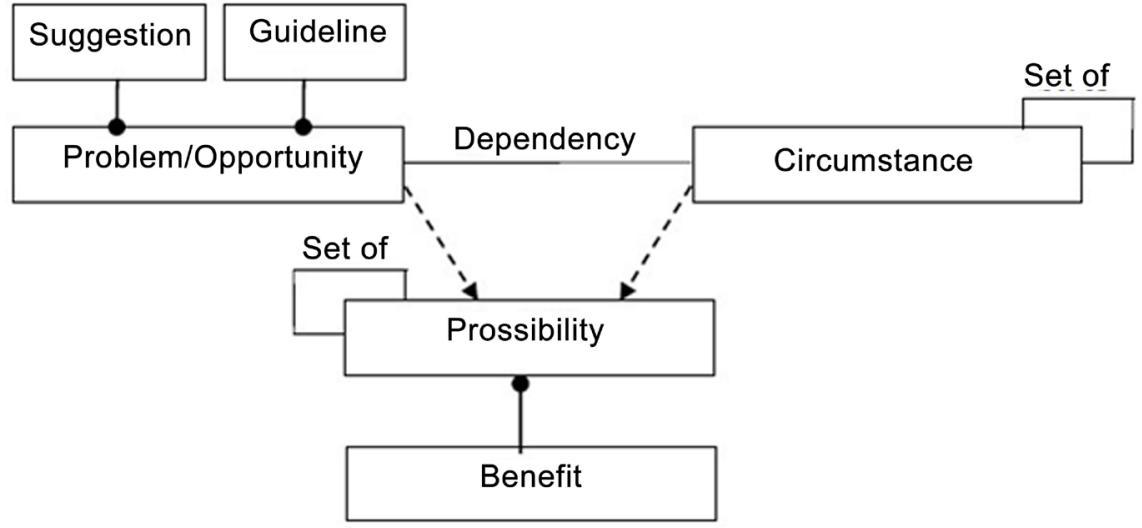

Figure 8. HER: element exam of situational difference.

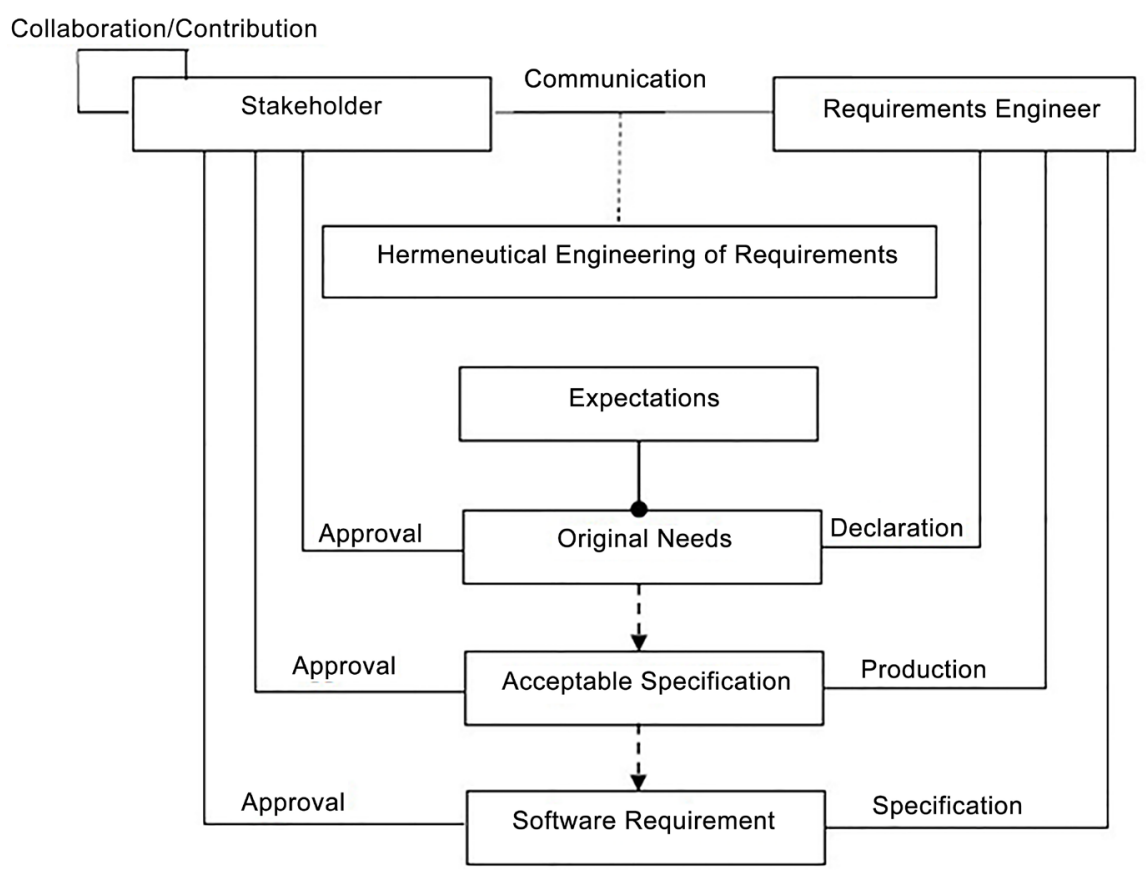

Figure 9. HER: element specification of requirements. 
The Requirements Engineer will state the unique needs of the stakeholders along with their expectations. In possession of this artifact, the requirements engineer will produce the acceptable specification, which will serve as a subsidy for specifying the software requirements. Each of these artifacts must be validated and approved by the stakeholder community. The communication between the requirements engineer and the interested parties will be through hermeneutic requirements engineering.

\section{Conclusions}

The requirements are associated with major software development problems. Requirements that do not reflect the unique needs of users, incomplete or inconsistent, changing requirements already agreed and hardship to get a common understanding among all stakeholders are the main difficulties identified in a project in which the software subsystem has a key role. These difficulties identified generate rework, delay of schedule, increased cost and dissatisfaction of users and customers, if the project is not canceled before.

In this paper, we present the central theme of a research project whose primary result is a proposal to develop solutions to problems related to Requirements Engineering, through the use of targeted hermeneutical methods for the interpretation of the original business requirements to be met, to produce an hermeneutics specification acceptable, which should be used for extraction and specification requirements of the software to be developed. The Hermeneutical Engineering of Requirements is the result of the adequacy of the concepts "Dasein" and "Hermeneutic Circle" proposed by Martin Heidegger, to specifically assist the Requirements Engineering activity, from Software Engineering.

\section{References}

[1] Project Smart (2014) The Standish Group Report-Chaos Report. https://www.projectsmart.co.uk/white-papers/chaos-report.pdf

[2] Pressman, R.S. (2011) Software Engineering. Translation Ariovaldo Griesi. AMGH, Porto Alegre.

[3] Portocarrero, M.L. (2010) Philosophical Hermeneutics. Coimbra University, Coimbra.

[4] Coelho, A. (2012) Being and Time. Heidegger (II): The Dasein (Being-There). http://aquitemfilosofiasim.blogspot.com.br/2012/02/ser-e-tempo-de-heidegger-ii-odasein.html

[5] Dasein, Clinical Psychology (2010) What Is Dasein? http://daseinpsicologia.blogspot.com.br/2010/03/o-significado-de-dasein-ser-no-m undo.html

[6] da Silva Roberto, L. (2009) The Ways of Being of the "Dasein" from Heidegger's Existential Analytic. http://pensamentoextemporaneo.com.br/?p=489

[7] de Oliveira, R.G. (2012) The Meaning of Death in the Existential Analysis of Dasein from Heidegger. http://pensamentoextemporaneo.com.br/?p=2408

[8] Silva, G.L. (2009) Gadamer and the Hermeneutic Circle. http://www.webartigos.com/artigos/gadamer-e-o-circulo-hermeneutico/25275/ 
Submit or recommend next manuscript to SCIRP and we will provide best service for you:

Accepting pre-submission inquiries through Email, Facebook, LinkedIn, Twitter, etc. A wide selection of journals (inclusive of 9 subjects, more than 200 journals)

Providing 24-hour high-quality service

User-friendly online submission system

Fair and swift peer-review system

Efficient typesetting and proofreading procedure

Display of the result of downloads and visits, as well as the number of cited articles Maximum dissemination of your research work

Submit your manuscript at: http://papersubmission.scirp.org/

Or contact jec@scirp.org 